\title{
Escala de Fontes de Autoeficácia para Escolha Profissional: Construção e Estudos Psicométricos Iniciais
}

\author{
Thaline da Cunha Moreira ${ }^{1, *}$ \\ Orcid.org/0000-0002-6484-8583 \\ Rodolfo Augusto Matteo Ambiel ${ }^{1}$ \\ Orcid.org/0000-0002-3921-8547 \\ Maiana Farias Oliveira Nunes ${ }^{2}$ \\ Orcid.org/0000-0003-4891-5982 \\ ${ }^{1}$ Universidade São Francisco, Campinas, SP, Brasil \\ ${ }^{2}$ Universidade Federal de Santa Catarina, Florianópolis, SC, Brasil
}

\section{Resumo}

A avaliação em orientação profissional pode envolver diversos construtos, entre eles o da autoeficácia para escolha profissional, que se refere às crenças quanto à capacidade de se engajar em atividades de decisão profissional. Contudo, a literatura ainda é incipiente quanto a avaliação das fontes de autoeficácia em tal domínio. Assim, o presente estudo teve por objetivo a construção da Escala de Fontes de Autoeficácia para Escolha Profissional (EFAEP). O processo de construção envolveu a formulação dos itens e a coleta piloto. Finalizado o processo de construção, deu-se início a coleta de dados, da qual participaram 388 estudantes das três séries do ensino médio, com idades entre 14 e 19 anos, de escolas públicas e particulares do interior do estado de São Paulo. Além da EFAEP, os alunos também responderam à Escala de Autoeficácia para Escolha Profissional (EAE-EP). Análises de componentes principais foram realizadas e uma estrutura com três fatores apresentou o melhor ajuste, com alfas de Cronbach variando entre 0,81 e 0,73 . Além disso, todos os fatores da EFAEP se correlacionaram positivamente com os fatores da EAE-EP. Os resultados e limitações do estudo são discutidos de acordo com a literatura sobre o assunto.

Palavras-chave: Autoeficácia, orientação profissional, avaliação psicológica.

\section{Career Choice Self-Efficacy Source Scale: Development and Initial Psychometric Studies}

\begin{abstract}
Assessment in career counseling can involve various constructs, including that of career choice selfefficacy, which refers to one's belief in one's ability to engage in career decision-making activities. However, the literature is still incipient in relation to the assessment of the sources of self-efficacy for
\end{abstract}

\footnotetext{
Endereço para correspondência: Universidade São Francisco, Campus de Campinas, Rua Waldemar César da Silveira, 105, Jardim Cura D’Ars, Campinas, SP, Brasil 13045-510. E-mail: thacmoreira@gmail.com, rodolfo. ambiel@usf.edu.bre maiananunes@mac.com Apoio: Coordenação de Aperfeiçoamento de Pessoal de Nível Superior (CAPES).
} 
making career choices. Accordingly, the present study's aim was to develop the Career Choice SelfEfficacy Source Scale (Escala de Fontes de Autoeficácia para Escolha Profissional, or EFAEP; initials in Portuguese). The development process involved the formulation of the items as well as pilot data collection. Upon concluding the scale's developmental phase, we began data collection, which enjoyed the participation of 388 students between the ages of 14 and 19 years from public and private high schools in the state of São Paulo. In addition to the EFAEP, the students also responded to the Career Choice Self-Efficacy Scale (Escala de Autoeficácia para Escolha Profissional, or EAE-EP; initials in Portuguese). Principal component analysis was performed, and a three-factor structure exhibited the best fit, with Cronbach's alphas ranging between 0.81 and 0.73 . Furthermore, all of the EFAEP's factors displayed positive correlations with the EAE-EP's factors. The study's results and limitations are discussed in relation to the literature on the subject.

Keywords: Self-efficacy, career counseling, psychological assessment.

\section{Escala de Fontes de Autoeficácia para Escolha Profissional: Construcción y Estudios Psicométricos Iniciales}

\section{Resumen}

La evaluación de la orientación vocacional puede envuelve diversos constructos, entre los cuales está la autoeficacia para decisión profesional, que se refiere a las convicciones de la capacidad de envolverse en la actividad de decisión profesional. Sin embargo, la literatura es incipiente como la evaluación de las fuentes de autoeficácia en la decisión profesional. De esta forma, el presente estudio tuvo el objetivo de construir la Escala de Fontes de Autoeficácia para Escolha Profissional (EFAEP). Lo proceso de elaboración implica la formulación de los ítems e la colecta piloto. Finalizando el proceso de elaboración, se Dio continuidad a la colecta de datos, de la cual participaron 388 estudiantes de los tres años de secundaria superior, con edades entre 14 y 19 años, de escuelas públicas y privadas del interior de São Paulo, Brasil. Además de la EFAEP, los estudiantes también respondiero la Escala de Autoeficácia para Escolha Profissional (EAE-EP). Fueron realizadas análisis de los principales componentes e de la una estructura de tres factores que presentó mejor ajuste, con alfas de Cronbach entre 0.81 y 0.73 . Además, todos los factores de EFAEP correlacionan positivamente con los factores de EAE-EP. Los resultados y limitaciones del estudios son discutidos de acuerdo con la literatura del asunto.

Palabras clave: Autoeficacia, orientación vocacional, evaluación psicológica.

As crenças de autoeficácia referem-se à confiança na própria capacidade para organizar e desempenhar determinadas ações para atingir certas realizações (Bandura, 1997). Este construto é parte elementar da Teoria Social Cognitiva (TSC), proposta por Bandura (1977), que apresenta a perspectiva de que a pessoa é o agente de suas ações e a concepção de que o indivíduo vive em uma relação dinâmica, denominada determinismo recíproco, que diz respeito às interações do comportamento, fatores ambientais e os fatores pessoais (Azzi, Vieira, Iaochite, Ferreira, \& Guerreiro-Casanova, 2014; Bandura, 2008; Pajares \& Olaz, 2008).
Com um importante papel dentre esses conceitos, as crenças de autoeficácia também propiciam a motivação humana, as realizações pessoais e os estados afetivos, sendo ainda um componente da autorregulação do comportamento e pensamento humano, agindo no quanto de esforço será investido em uma tarefa, na persistência e resiliência diante das dificuldades (Bandura, 2009; Pajares, 2002; Pajares \& Olaz, 2008). Essas crenças configuram-se como um conjunto de auto-crenças dinâmicas, agindo em uma determinada situação (Lent, Brown, \& Hackett, 1994). Elas podem ser aplicadas em um domínio específico de desempenho, como por 
exemplo, relacionada à disciplina de ciências (Britner \& Pajares, 2006) e matemática (Usher \& Pajares, 2009), como também no contexto do desenvolvimento de carreira (Betz \& Luzzo, 1996), além de poderem ser avaliadas de forma geral, tendo, no entanto, utilidade mais restrita neste caso (Bandura, 1997).

As crenças de autoeficácia são construídas a partir de quatro fontes de informação, quais sejam, experiência pessoal (enactive mastery experience), aprendizagem vicária (vicarious experience), persuasão verbal (verbal persuasion) e indicadores fisiológicos (phisiological and affective states) (Bandura, 1997). Neste estudo, optou-se por adotar a nomenclatura das fontes tais como sugeridas por Nunes e Noronha (2011).

A primeira fonte, denominada de experiências pessoais, é a de maior influência na formação das crenças de autoeficácia, por se tratar da interpretação de experiências realizadas anteriormente. Essa fonte fornece informações legítimas a respeito do comportamento do indivíduo, indicando-lhe a possibilidade de atingir ou não o sucesso em certa atividade (Bandura, 1997; Pajares, 2002). As situações de sucesso tendem a intensificar as crenças de autoeficácia, já o fracasso tende a enfraquecê-las, principalmente quando acontece precocemente ou não agrega uma informação relevante sobre o próprio esforço. As novas experiências são "dosadas" de acordo com as percepções que a pessoa já possui, desta forma vão sendo integradas às crenças anteriores (Nunes, 2008).

A segunda fonte, chamada de aprendizagem vicária, diz respeito à observação de outras pessoas executando uma determinada tarefa e à inferência do próprio nível de capacidade a partir da comparação com outros considerados semelhantes (Pajares, 2002). Essa fonte de informação tende a ser menos eficiente que a primeira, porém pode ser relevante quando as pessoas estão com dúvidas sobre a sua capacidade ou não possuem experiências anteriores em um dado domínio. A visualização do outro obtendo sucesso ou fracasso em uma atividade pode tanto elevar como reduzir os julgamentos de autoeficácia (Bandura, 1997; Pajares, 2002).
A terceira fonte, denominada de persuasão verbal, refere-se aos julgamentos verbais de outras pessoas, transmitidos em formato de $f e$ edbacks, tanto positivos quanto negativos, que podem tanto aumentar as crenças de capacidade como também enfraquecê-las (Pajares, 2002). Essa fonte terá utilidade limitada se não houver possibilidades reais de a pessoa conquistar uma tarefa com sucesso, porém, quando houver feedbacks positivos, um maior esforço poderá ser reunido para desempenhar a ação requerida. $\mathrm{O}$ impacto das persuasões verbais ainda será maior na formação das crenças de autoeficácia quando o indivíduo acreditar que há alguma probabilidade do seu comportamento produzir o resultado esperado (Bandura, 1997).

A quarta e última fonte de autoeficácia trata dos indicadores fisiológicos, que podem ocorrer por meio da auto-avaliação dos estados de ansiedade, estresse e humor. As pessoas conseguem obter alguma informação sobre a sua própria capacidade por meio da avaliação do seu estado emocional e fisiológico durante a realização de uma atividade. Essas reações físicas e emocionais atuam como um indicativo de sucesso ou fracasso na atividade. $\mathrm{O}$ temor, o medo e os pensamentos negativos sobre a própria capacidade podem desencadear baixas percepções de autoeficácia, gerando um estresse e, consequentemente, um desempenho fraco. Para elevar as crenças de autoeficácia é pertinente que ocorra a promoção do bem-estar emocional e redução dos estados emocionais negativos (Pajares, 2002; Pajares \& Olaz, 2008).

As fontes de autoeficácia fornecem informações relevantes para a formação dos julgamentos de autoeficácia, sendo integradas a eles por meio do processamento cognitivo e reflexivo. Além disso, os elementos pessoais, sociais e ambientais podem afetar como essas informações serão interpretadas pelo indivíduo (Bandura, 1997). Desta forma, as quatro fontes de informações não são responsáveis por produzir uma avaliação "direta" da percepção de capacidade, pois é a partir das interpretações que as pessoas realizam das situações vivenciadas que surgem os julgamentos de competência, a percepção de sua vulnerabilidade e força, contribuindo para o 
fortalecimento ou enfraquecimento das crenças de autoeficácia (Nunes, 2008; Pajares \& Olaz, 2008).

As fontes de autoeficácia podem operar independentemente ou de forma simultânea, assim as pessoas ao mesmo tempo em que avaliam as suas experiências anteriores e os esforços que investem em uma tarefa também observam o comportamento de pessoas semelhantes a elas, recebem algum tipo de feedback sobre o seu desempenho e avaliam o seu estado físico e emocional. Como as fontes interagem mutuamente, cada uma pode exercer uma maior influência na formação das crenças, dependendo da sua força (Nunes, 2008).

As informações que as fontes fornecem para a formação das crenças de autoeficácia podem ser recebidas dos mais diversos ambientes em que a pessoa se encontra, variando de acordo com a cultura em que está inserida e no domínio em que está sendo aplicada (Ahn, Usher, Butz, \& Bong, 2016). Como visto anteriormente, o construto da autoeficácia deve ser aplicado em contextos específicos de desempenho, como por exemplo, pode ser investigada no contexto da orientação profissional (Nunes \& Noronha, 2011).

No contexto dos estudos sobre carreira, a Teoria Social Cognitiva de Desenvolvimento de Carreira (TSCDC), proposta por Lent et al. (1994), tem se destacado. Por meio dela os autores apresentaram uma estrutura teórica para compreender o desenvolvimento de carreira, sendo contextualizado em três etapas, que são: a formação dos interesses profissionais; as escolhas acadêmicas e profissionais; e o desempenho nessas atividades. Para a elaboração desta teoria, o principal referencial teórico foi a TSC de Bandura (1977), da qual dois construtos foram utilizados como ponto central, que foram a autoeficácia e as expectativas de resultados (Lent et al., 1994).

A TSCDC é entendida como um avanço da proposta de Hackett e Betz (1981), que foram as pioneiras quanto à aplicação da autoeficácia no contexto do desenvolvimento de carreira em mulheres. Mais tarde, Taylor e Betz (1983) apresentaram um instrumento para avaliar este construto, que foi denominado Career Decision-Making Self-Efficacy Scale (CDMSES). O termo em inglês Career Decision-Making Self-Efficacy foi compreendido e traduzido por Ambiel e Noronha (2012a) como autoeficácia para escolha profissional, que se refere à confiança das pessoas para se engajarem nas atividades relacionadas ao processo de escolha profissional.

Desde então, a avaliação do construto se consolidou em diversos países, originando estudos de aprimoramento da escala e até mesmo a criação de outros instrumentos a partir dela. No Brasil, Ambiel e Noronha (2012a) elaboraram uma escala para avaliar este construto, a Escala de Autoeficácia para Escolha Profissional (EAE-EP), que tem por objetivo avaliar as crenças das pessoas na própria capacidade para se envolverem em atividades de escolha profissional, e é composta por quatro fatores, a saber, autoavaliação, coleta de informações ocupacionais, busca de informações profissionais práticas e planejamento de futuro, além de um escore total (Ambiel \& Noronha, 2012b). Estudos recentes constataram a consistência da estrutura da escala e a adequação de seus itens (Ambiel, Noronha, \& Carvalho, 2015).

Anteriormente, abordando outro domínio no contexto da orientação profissional, Nunes e Noronha $(2008,2011)$ apresentaram um instrumento denominado Escala de Autoeficácia para Atividades Ocupacionais (EAAOc), com o intuito de avaliar o senso de capacidade para executar certas atividades profissionais, segundo a tipologia de interesses de Holland. Nesse instrumento, as autoras propuseram ainda uma sessão para avaliar as fontes de autoeficácia para as atividades e encontraram dois fatores, relativos às experiências autênticas (que agregou experiências pessoais, persuasão verbal e indicadores fisiológicos) e, outro, à aprendizagem vicária.

$\mathrm{Na}$ revisão de literatura realizada, esse foi o único instrumento encontrado no Brasil para a avaliação das fontes de autoeficácia no contexto de carreira, além dele, no âmbito nacional há uma escala para avaliar tal construto relacionado ao corpo docente (Iaochite \& Azzi, 2012). No contexto estrangeiro, percebem-se estudos com o construto em outras áreas, tais como os apli- 
cados à disciplina de matemática (Lent, Lopez, Brown, \& Gore, 1996; Usher, 2009; Usher \& Pajares, 2009) e ciências (Britner \& Pajares, 2006); à escrita dos estudantes (Pajares, Johnson, \& Usher, 2007) e ao contexto acadêmico (Ahn et al., 2016; Hampton \& Mason, 2003; Joët, Bressoux, \& Usher, 2011; Usher \& Pajares, 2006, 2008). A maioria dos estudos ocorreram nos Estados Unidos (EUA).

Avaliar as fontes de autoeficácia para escolha profissional se torna relevante para potencializar a intervenção e o desenvolvimento das crenças de autoeficácia, uma vez que essa crença proporciona às pessoas maior segurança e menos ansiedade no processo de escolha de uma carreira (Lent et al., 1994). Além disso, os adolescentes, que são os principais protagonistas deste momento de escolha profissional estão suscetíveis às influências externas e internas, que agem diretamente na construção das suas crenças de autoeficácia (Lopes \& Teixeira, 2012; Matias et al., 2009)

Devido à importância das fontes de autoeficácia neste contexto, o objetivo deste estudo é relatar o processo de construção da Escala de Fontes de Autoeficácia para Escolha Profissional, bem como buscar de evidências de validade baseada na estrutura interna, e na relação com outras variáveis e a estimação de seus índices de precisão. Assim, dada a importância de fornecer ferramentas com boas propriedades psicométricas para a prática do psicólogo em orientação profissional, o instrumento apresentado neste artigo ganha destaque, provendo possibilidades de interpretação de dados oriundos da Teoria Social Cognitiva e sua aplicação no contexto de desenvolvimento de carreira de adolescentes.

Construção da Escala de Fontes de Autoeficácia para Escolha Profissional (EFAEP)

Para a construção da Escala de Fontes de Autoeficácia para Escolha Profissional (EFAEP), dois instrumentos foram utilizados como referência. A seção de avaliação das fontes de autoeficácia da Escala de Autoeficácia para Atividades Ocupacionais (EAAOc), de Nunes e Noronha (2011), foi o principal modelo, enquanto que a Escala de Autoeficácia para Escolha
Profissional (EAE-EP), de Ambiel e Noronha (2012b) foi utilizada por se tratar de uma medida de autoeficácia neste domínio e servir para validade convergente.

Assim, os itens da escala de fontes da EAAOc foram reescritos contemplando os fatores propostos na EAE-EP, quais sejam, Autoeficácia (AE) para autoavaliação, AE para coleta de informações ocupacionais, AE para busca de informações profissionais práticas e AE para planejamento de futuro. Dessa forma, buscou-se obter itens, por meio de adaptação do texto daqueles já existentes na EAAOc ou da formulação de novos itens, que fossem relativos à uma determinada fonte para um fator específico de autoeficácia para escolha profissional. Por exemplo, o item "Sinto-me bem quando faço essa atividade", que originalmente avaliava a fonte Experiência Pessoal da EAAOc foi adaptado para avaliar a mesma fonte, mas em relação à autoeficácia para escolha profissional e ficou da seguinte forma: "Sinto-me bem quando penso em escolher a profissão com a qual me identifico". Assim, um total de 145 itens foram gerados.

Finalizada essa etapa, os itens foram enviados por e-mail para uma das autoras da EAAOc, que realizou a análise dos mesmos e pontuou principalmente algumas correções quanto à redação deles. Como esperado, a maioria foi descartada por conta da semelhança de conteúdo e, com isso, 44 itens foram mantidos, sendo estes os que receberam as melhores avaliações da autora da EAAOc, com as propostas de correção e alteração gramatical acatadas. Após uma revisão geral, observou-se que muitas afirmativas ainda estavam com os enunciados parecidos, indicando a necessidade de modificações. Com estes ajustes, mais 9 itens foram excluídos, totalizando 35 itens que foram efetivamente aproveitados para a versão preliminar da nova escala. Terminado esse processo, notou-se que nessa fase da construção do instrumento as fontes de autoeficácia não estavam sendo representadas de forma proporcional. Assim, foram elaboradas 14 novas afirmativas, que junto aos que foram adaptados, totalizaram 49 itens.

Em continuidade a esse processo, as 49 afirmativas foram enviadas novamente para a 
avaliação de uma das autoras da EAAOc. Os comentários e sugestões nessa fase ocorreram de forma pontual, indicando alterações na redação dos itens e a exclusão de um por semelhança de conteúdo. Encerrada a construção do instrumento, a EFAEP foi finalizada com um total de 48 itens, sendo 8 para a fonte de persuasão verbal, 10 para a fonte de experiência pessoal, 12 para a fonte de indicadores fisiológicos e 18 para a fonte de aprendizagem vicária. Quanto às instruções para a chave de resposta, optou-se por manter o formato original da EAAOc, com escala Likert de cinco pontos, na qual os valores próximos de 1 significam "menor concordância" quanto às situações descritas nas frases e próximos de 5 "maior concordância".

$\mathrm{Na}$ segunda etapa de construção da EFAEP, iniciou-se a coleta piloto, que ocorreu com cinco estudantes do ensino médio, participantes mediante a entrega do Termo de Consentimento Livre e Esclarecido assinado pelo responsável. A aplicação ocorreu individualmente, em locais variados. Os participantes foram convidados a responder o instrumento e uma ficha de avaliação sobre a compreensão das instruções e das frases.

A maioria não encontrou dificuldades em compreender os itens e apenas um ressaltou a necessidade de melhorar as instruções quanto à chave de resposta. Com o término da coleta piloto e indicação deste aluno a escala passou por uma nova revisão, na qual as instruções sobre a chave de resposta foram alteradas para melhor compreensão, ficando como: valores próximos de 1 significam que você "concorda pouco" quanto às situações descritas nas frases e próximos de 5 que você "concorda muito". Assim, a construção do instrumento foi encerrada e deu-se início a fase da coleta de dados para as outras evidências de validade e precisão.

\section{Método}

\section{Participantes}

A amostra foi composta por 388 estudantes, com $61,6 \%$ do sexo feminino e $38,4 \%$ do sexo masculino e faixa etária entre 14 e 19 anos $(M=15,9 ; D P=1,0)$. Os participantes foram pro- venientes de duas escolas públicas, sendo uma de ensino técnico $(n=92)$ e outra de ensino médio regular $(n=66)$, de uma escola particular $(n=56)$, de um colégio SESI $(n=67)$ e de uma associação de jovens aprendizes $(n=107)$. Todas as instituições de ensino localizam-se em três cidades do interior do estado de São Paulo.

\section{Instrumentos}

A Escala de Fontes de Autoeficácia para Escolha Profissional (EFAEP) é composta por 48 itens, que avaliam as fontes de autoeficácia dos estudantes de ensino médio, usadas para construir ou fortalecer as crenças de autoeficácia para se envolverem nas atividades de escolha profissional. Na seção "Resultados" são apresentados exemplos de itens, bem como as análises que foram realizadas com o instrumento. A chave de resposta é em escala Likert de cinco pontos, na qual valores próximos de 1 significam que "concorda pouco" e próximos de 5 "concorda muito" com as situações descritas nas frases.

A Escala de Autoeficácia para Escolha Profissional (EAE-EP) também foi utilizada, tendo sido construída por Ambiel e Noronha (2012b). Tem por objetivo avaliar as crenças de uma pessoa quanto à sua capacidade para se envolver nas tarefas de escolha profissional. Ela é composta por 47 itens, distribuídos em quatro fatores, sendo eles autoeficácia para autoavaliação, coleta de informações ocupacionais, busca de informações profissionais práticas, planejamento de futuro e o escore geral. A chave de resposta é em escala do tipo Likert de 4 pontos, em que é a avaliada a intensidade da crença, sendo 1 "pouco" e 4, "muito". A estrutura fatorial deste instrumento foi obtida a partir de estudos de análise fatorial, apresentando boa precisão, com o coeficiente alfa de Cronbach variando entre 0,79 e 0,88 para os fatores e de 0,94 para o escore geral. Neste estudo, os Alfas variaram entre 0,75 e 0,86 para os fatores e 0,92 para o escore geral.

\section{Procedimentos de Coletas de Dados}

As coletas aconteceram com dias e horários previamente agendados com as escolas, sendo que participaram da pesquisa apenas os estudantes que entregaram o Termo de Consentimento 
Livre e Esclarecido (TCLE) assinado pelo responsável ou por ele mesmo, quando maior de 18 anos. Primeiramente aplicou-se a EFAEP, seguida da EAE-EP. O tempo médio para responder aos instrumentos foi de aproximadamente 30 minutos.

\section{Procedimentos de Análise de Dados}

Os dados foram tabulados em uma planilha eletrônica e analisados por meio do programa estatístico SPSS v.20. Os casos de missing na base de dados não interferiram nas análises, desta forma nenhum participante precisou ser excluído. Primeiramente foi realizada a análise de componentes principais para verificar a estrutura interna da EFAEP. Para tanto, utilizou-se de uma análise paralela com o intuito de obter a quantidade de itens a serem retidos nos componentes.

Essa análise consiste em uma simulação de matrizes aleatórias que são rodadas centenas ou milhares de vezes, com o mesmo número de variáveis e sujeitos da base de dados real. Uma comparação entre os eigenvalues aleatório e real é realizada, sendo retidos aqueles que apresentam um valor maior do que 1 e menor que o valor aleatório obtido (Damásio, 2012). No presente estudo, a análise paralela foi realizada por meio do site Parallel Engine (Patil, Singh, Mishra, \& Donovan, 2007), utilizando 1000 matrizes e um intervalo de confiança de $95 \%$. Também foi verificada a consistência interna dos fatores por meio do coeficiente alfa de Cronbach. Para a avaliação das correlações entre os instrumentos, foi utilizado o coeficiente $r$ de Pearson com atenuação pelos erros de medida dos instrumentos, para tanto foi utilizado o ajuste de Spearman-Brown, segundo a estratégia sugerida por Cohen e Cohen (1983).

\section{Procedimentos Éticos}

Inicialmente foi estabelecido o contato com as instituições de ensino para solicitar a participação dos alunos na presente pesquisa. Após a autorização das escolas, o projeto foi encaminhado e aprovado por um Comitê de Ética em Pesquisa. Além disso, durante a coleta de dados, atendeu-se a todos os cuidados éticos exigidos em pesquisas realizadas com seres humanos.

\section{Resultados}

A análise de componentes principais para a EFAEP foi realizada com rotação direct oblimin, obtendo um $\mathrm{KMO}=0,86$ e teste de esfericidade de Bartlett significativo ao nível de $p<0,001$. Também foi indicada a fatoração do conjunto de itens com possibilidade de até 13 componentes com eigenvalues maiores do que 1, pelo critério de Kaiser. Com a realização da análise paralela identificou-se a possibilidade de extração de até sete fatores, porém, optou-se, com base na literatura sobre as fontes de autoeficácia, forçar uma estrutura com até quatro fatores, obtendo-se um total de $37 \%$ da variância explicada. Para a manutenção dos itens utilizou-se como critério manter aqueles com carga fatorial igual ou superior a 0,30 . Com isso, foram eliminados sete itens do total de 48 .

A estrutura com quatro fatores ficou composta da seguinte maneira: o fator 1 com 12 itens, em sua maioria, afirmativas relativas a fonte de persuasão verbal, no entanto três itens foram agrupados neste componente com conteúdos diferentes do proposto para esta fonte. $\mathrm{O}$ fator 2 agrupou 9 itens, parte deles com conteúdos relativos à fonte de aprendizagem vicária e a outra parte relativos à fonte de indicadores fisiológicos. Por apresentar um conjunto de itens problemáticos, ou seja, que reuniram itens com redação ambígua, não foi possível estabelecer a qual fonte de autoeficácia eles realmente pertenciam. No fator 3 , foram alocados 10 itens relacionados à fonte de autoeficácia de aprendizagem vicária. E, por fim, o fator 4 reuniu também 10 itens representando a fonte de experiências pessoais. Com essa estrutura de até quatro fatores foi possível identificar que dois componentes apresentaram um conjunto problemático de itens, em função dos mesmos misturarem itens de mais de um fator. $O$ fator 1 possuía três itens discrepantes para a fonte que estava representado e, o fator 2 misturou itens relativos à duas fontes de autoeficácia.

Após revisão da literatura quanto às fontes de autoeficácia e análise dos itens da escala, identificou-se que aqueles construídos para abordar a fonte de indicadores fisiológicos foram es- 
critos contemplando principalmente as questões afetivas em relação à escolha profissional, sem considerar também as questões fisiológicas. Importante ressaltar que a fonte de autoeficácia denominada indicadores fisiológicos corresponde à avaliação que o indivíduo realiza de sua confiança para executar uma determinada atividade, com base nas informações fornecidas pelo seu estado fisiológico e emocional (Nunes, 2008). Assim, o instrumento não conseguiu reunir itens que representassem adequadamente a fonte de indicadores fisiológicos, a ponto de representar um fator específico.

Por conta da problemática encontrada na estrutura com quatro fatores, uma nova análise de componentes principais foi realizada, antes disso foram excluídos os 12 itens que apresen- taram problemas com essa estrutura. Para a nova análise utilizou-se a rotação direct oblimin, obtendo um $\mathrm{KMO}=0,86$ e teste de esfericidade de Bartlett significativo ao nível de $p<0,001$. Com a análise paralela identificou-se a possibilidade de extrair até três componentes, forçando-se então tal estrutura, obtendo $40 \%$ de variância explicada. Repetiu-se o uso do critério para manutenção dos itens (carga fatorial maior que 0,30 ). Uma estrutura com dois componentes também foi avaliada, porém com três fatores apresentou um ajuste mais adequado, tanto do ponto de vista psicométrico como teórico. Com o agrupamento de três componentes, mais 11 itens foram excluídos, por não obterem a carga fatorial estipulada, totalizando 23 itens descartados, permanecendo um total de 25 , como pode ser visto na Tabela 1 .

Tabela 1

Agrupamento dos Itens da EFAEP nos Fatores - Estrutura com Três Fatores

\begin{tabular}{|c|c|c|c|c|}
\hline & \multirow{2}{*}{ Itens } & \multicolumn{3}{|c|}{ Fatores } \\
\hline & & 1 & 2 & 3 \\
\hline 47 & $\begin{array}{l}\text { Fico bem disposto quando acompanho o dia de um profissional } \\
\text { da área que eu gosto }\end{array}$ & 0,69 & & \\
\hline 45 & $\begin{array}{c}\text { Eu vejo que os alunos dos cursos do meu interesse possuem } \\
\text { características parecidas com as minhas }\end{array}$ & 0,64 & & \\
\hline 10 & Fico feliz ao realizar uma visita a uma empresa da área que quero trabalhar & 0,64 & & \\
\hline 23 & Participar de palestras na área que eu quero trabalhar me deixa feliz & 0,59 & & \\
\hline 34 & $\begin{array}{l}\text { Eu percebo que tenho habilidades parecidas com as dos profissionais } \\
\text { da área que gosto }\end{array}$ & 0,55 & & \\
\hline 29 & $\begin{array}{l}\text { Sinto-me realizado ao fazer uma atividade parecida com a profissão } \\
\text { que quero escolher }\end{array}$ & 0,54 & & \\
\hline 35 & Costumo observar profissionais na área para aprender sobre o que eles fazem & 0,45 & & \\
\hline 37 & Conhecer a atividade desempenhada por um profissional que admiro me anima & 0,44 & & \\
\hline 22 & $\begin{array}{c}\text { Tenho observado que os profissionais da área do meu interesse } \\
\text { possuem opiniões com as quais me identifico }\end{array}$ & 0,39 & & \\
\hline 46 & Geralmente recebo elogios pela maneira como eu planejo o meu futuro & & 0,85 & \\
\hline 30 & $\begin{array}{l}\text { Minha família costuma dizer que fica orgulhosa pela forma que me } \\
\text { preocupo com o meu futuro }\end{array}$ & & 0,79 & \\
\hline 13 & Recebo elogios pela forma como procuro organizar meu futuro profissional & & 0,76 & \\
\hline 5 & $\begin{array}{c}\text { Costumo receber elogios pela maneira como realizo pesquisas sobre } \\
\text { cursos e profissões }\end{array}$ & & 0,58 & \\
\hline 2 & Geralmente dizem que eu conheço bastante sobre os cursos e profissões & & 0,58 & \\
\hline
\end{tabular}


Sei como posso obter informações sobre quanto um profissional pode ganhar

Sinto-me motivado quando faço um balanço do retorno que esta profissão pode me trazer

Fico tranquilo quando penso no retorno financeiro que a profissão de meu interesse pode me trazer

O uso de computador tem facilitado encontrar informações sobre cursos superiores

12 Sei detalhes sobre as habilidades que devo ter para fazer o curso que gosto

O Fator 1 alocou os itens correspondentes à fonte de autoeficácia denominada Aprendizagem Vicária, com um total de 9 itens e um alfa de Cronbach de 0,80 . Observaram-se nesse fator que foram agrupados quatro itens escritos para representar especificamente a fonte de aprendizagem vicária como também reuniu cinco itens elaborados para contemplar a fonte de indicadores fisiológicos, porém apesar de haver mais itens desta última fonte, nota-se que os mesmos possuem um conteúdo ambíguo e que a sua interpretação é mais representativa para a fonte de aprendizagem vicária. No Fator 2 ficaram os itens relativos a fonte de Persuasão verbal, e que se tratam das afirmativas escritas para representar especificamente esta fonte. Este fator ficou composto por 7 itens e com a consistência de 0,81 .

Por fim, o Fator 3 reuniu 9 itens referentes a fonte de Experiências Pessoais, obtendo um alfa de 0,73 . Os itens aqui agrupados foram na maioria escritos para contemplar a fonte de experiências pessoais, no entanto duas afirmativas escritas para as fontes de indicadores fisiológicos e uma de aprendizagem vicária se uniram a este fator. Com essa estrutura, a Escala de Fontes de Autoeficácia para Escolha Profissional conseguiu representar de forma satisfatória três fontes de autoeficácia para o contexto da escolha profissional.

Com a intenção de buscar evidências de validade com base na relação com outras variáveis, após a realização da análise fatorial com a EFAEP, foi verificada a correlação entre os seus fatores e os da EAE-EP. No caso, foi realizada a atenuação das correlações, controlando o efeito dos erros de medida de ambos os instrumentos. Na Tabela 2 são apresentados os coeficientes encontrados. 
Tabela 2

Correlações Atenuadas entre os Fatores da EFAEP e a EAE-EP

\begin{tabular}{cccccc}
\hline Fontes de autoeficácia & $\begin{array}{c}\text { Autoeficácia } \\
\text { para } \\
\text { autoavaliação }\end{array}$ & $\begin{array}{c}\text { Autoeficácia para a } \\
\text { coleta de informações } \\
\text { ocupacionais }\end{array}$ & $\begin{array}{c}\text { Autoeficácia para a } \\
\text { busca de informações } \\
\text { profissionais práticas }\end{array}$ & $\begin{array}{c}\text { Autoeficácia para } \\
\text { o planejamento } \\
\text { de futuro }\end{array}$ \\
\hline Aprendizagem vicária & $r$ & $0,59^{*}$ & $0,46^{*}$ & $0,63^{*}$ & $0,32^{*}$ \\
Persuasão Verbal & $r$ & $0,55^{*}$ & $0,55^{*}$ & $0,44^{*}$ & $0,34^{*}$ \\
Experiência Pessoal & $r$ & $0,47^{*}$ & $0,56^{*}$ & $0,66^{*}$ \\
\hline
\end{tabular}

$* p \leq 0,001$.

Pode-se observar que todas as correlações foram positivas e significativas, com magnitudes variando entre baixas e moderadas, de acordo com as indicações de Dancey e Reidy (2006). Destas relações destacam-se as que tiveram as maiores magnitudes que foram entre a fonte de aprendizagem vicária com a os fatores autoeficácia para busca de informações profissionais práticas $(r=0,63)$ e para autoavaliação $(r=0,59)$, e a fonte de experiência pessoal com autoeficácia para planejamento de futuro $(r=0,66)$.

\section{Discussão}

A escolha profissional é um momento complexo na vida do adolescente e com diversas variáveis agindo sobre a sua decisão. Nessa fase da vida, a psicologia, por meio do processo de orientação profissional, disponibiliza algumas ferramentas que podem contribuir para o esclarecimento das dúvidas e organização das informações que são fornecidas ao jovem (Noronha \& Ambiel, 2006). É neste contexto que a avaliação da autoeficácia e suas fontes se torna relevante, por proporcionar ao adolescente a análise das atividades na qual acredita ter um bom desempenho e expectativas de resultados positivos (Lent et al., 1994). Com isso, o presente estudo teve como objetivo relatar o processo de construção da Escala de Fontes de Autoeficácia para Escolha Profissional (EFAEP), que possibilita avaliar as fontes de informação de autoeficácia utilizadas na formação, bem como no fortalecimento e enfraquecimento das crenças de autoeficácia dos adolescentes.
Para a construção da EFAEP, procurou-se criar itens para permitir a avaliação das quatro fontes de autoeficácia, tendo como base o estudo apresentado por Bandura (1997). A EAAOc, um dos instrumentos utilizados como base para a construção da EFAEP é composto em sua versão mais atual por dois fatores, que avaliam as fontes de informação de autoeficácia, agrupadas em dois núcleos, sendo um voltado puramente para a aprendizagem vicária e o outro para as experiências autênticas que ocorrem com as pessoas, sendo relativa às fontes de experiência pessoal, persuasão verbal e indicadores fisiológicos (Nunes \& Noronha, 2011). O outro instrumento utilizado como referência de uma medida da autoeficácia no contexto da escolha profissional, proporcionou embasar os itens da EFAEP quanto a esta área do desenvolvimento de carreira. A construção das afirmativas priorizou o momento específico de escolha por um curso superior ou profissão.

No que diz respeito às análises de componentes principais realizadas com a EFAEP, observou-se que não foi possível agrupá-los em quatro fatores, o que estaria de acordo com o suporte teórico a respeito das fontes de autoeficácia (Bandura, 1997). A principal causa identificada neste descompasso com a teoria se refere à forma como os itens foram escritos para contemplar a fonte de indicadores fisiológicos. Segundo Pajares (2002), por meio do estado emocional e fisiológico as pessoas podem avaliar se serão capazes de desempenhar uma determinada atividade. Após revisão teórica, notou-se que os itens desta fonte não consideraram o estado fi- 
siológico no momento da escolha profissional, focando principalmente no aspecto emocional e afetivo, sendo importante ressaltar que tal fonte de autoeficácia é composta tanto pelos estados emocionais como também os fisiológicos. As reações mais frequentes como estresse, taquicardia e sudorese podem se apresentar em diversas situações e o nível em que elas se manifestam é julgado como um indicativo de capacidade.

Pelo fato de não trazer tais aspectos nos itens, não foi possível atender ao objetivo de avaliar as fontes de autoeficácia em quatro fatores. A estrutura com quatro fatores também não foi encontrada em outras pesquisas, como é o caso do estudo de Nunes e Noronha (2008, 2011) que inicialmente apresentaram uma estrutura com três e depois dois fatores para a EAAOc. Da mesma forma, Anderson e Betz (2001) e Gainor e Lent (1998) em suas investigações evidenciaram diferentes composições.

Além disso, houve uma tendência dos itens relativos às fontes de aprendizagem vicária e indicadores fisiológicos se agruparem, o que se observa tanto na primeira composição com quatro fatores como na estrutura adotada para o instrumento com três fatores. Isso pode ser atribuído a forma como os itens foram elaborados, contendo certa ambiguidade no seu conteúdo e, assim, podendo ser interpretados como itens relativos às duas fontes de autoeficácia. Na estrutura adotada com três fatores, ficou ainda mais evidente que as afirmativas escritas para contemplar a fonte de indicadores fisiológicos possuíam um conteúdo ambíguo e mais representativo da fonte de aprendizagem vicária, o que foi primordial para determinar que o fator 1 da EFAEP se propõe a avaliação desta fonte, do que de indicadores fisiológicos.

Algo que pode ser observado é que a EFAEP agrupou no terceiro fator, relativo às fontes de autoeficácia de experiência pessoal, os itens referentes às experiências anteriores realizadas pela pessoa com enfoque nas questões de planejamento de futuro, seja pela escolha por um curso superior como por uma profissão e seu retorno financeiro. Esse conteúdo relativo à autoeficácia para escolha profissional corrobora com os dados que são avaliados pela EAE-EP, que possui um fator específico para avaliar o planejamento de futuro com enfoque nas questões financeiras (Ambiel \& Noronha, 2012b).

De fato, os resultados também demonstram que alguns ajustes são necessários para o melhor aproveitamento da escala, principalmente no que se refere à revisão e construção de novos itens, bem como a realização de uma análise de juízes. Ainda assim, contando com a exclusão dos itens que não apresentaram um bom funcionamento nesta composição, nota-se que os fatores ficaram compostos por uma quantidade proporcional de itens e que os mesmos possuem coerência teórica, possibilitando um equilíbrio quanto à avaliação das fontes e obtendo-se evidência de validade baseada na estrutura interna favorável. Do ponto de vista psicométrico, a escala apresentou bons ajustes de confiabilidade interna, apresentado nos três componentes apenas um com ajuste abaixo de 0,80 (Prieto \& Muñiz, 2000).

A partir das correlações realizadas entre os fatores da EFAEP e EAE-EP também se observou a relação entre os construtos, o que vai ao encontro da teoria quanto às fontes e às crenças de autoeficácia. Além disso, as maiores magnitudes corroboram a relação mais específica entre os fatores, como pode ser visto entre a fonte de aprendizagem vicária e a autoeficácia para busca de informações profissionais práticas, que possuem em comum o fato de observar e buscar no outro informações que o auxiliem na decisão por uma profissão. Da mesma forma, pode ser observada a relação entre a fonte de experiência pessoal e o fator autoeficácia para planejamento de futuro, que como descrito anteriormente, contém em seus itens um foco nas questões de carreira futura, considerando principalmente o aspecto financeiro. A partir destas correlações também foi obtida a evidência de validade baseadas nas relações com variáveis externas.

\section{Considerações Finais}

A necessidade de construção de instrumentos de avaliação com qualidades psicométricas adequadas é cada vez maior no campo da avaliação psicológica e principalmente na orientação profissional. O presente estudo buscou atender 
a essas demandas, de forma que, a longo prazo, essa ferramenta seja disponibilizada para o uso profissional do psicólogo. Além disso, este trabalho também contribui para a divulgação da autoeficácia e suas fontes aplicadas à orientação profissional no contexto brasileiro, algo que ainda é pouco explorado pelos pesquisadores.

A apresentação deste instrumento também é pertinente para o contexto da pesquisa, uma vez que disponibiliza uma ferramenta que permite testar as hipóteses teóricas da TSCDC, como verificar a capacidade preditiva das fontes de autoeficácia para as crenças de autoeficácia para escolha profissional. Quanto à importância desta escala para a avaliação psicológica, o conhecimento e averiguação das fontes de informações que os jovens utilizam na formação das crenças de autoeficácia é relevante por ser um caminho de auxílio ao jovem no momento crítico de escolha por um curso superior e por uma profissão.

Apesar disso, a EFAEP possui limitações, como o fato de não apresentar uma estrutura fatorial representando claramente as quatro fontes de autoeficácia. Essa problemática pode ter ocorrido pelo fato das fontes de indicadores fisiológicos não terem priorizado as questões fisiológicas quanto à escolha profissional, mas também pode ser atribuída a ambiguidade presente no conteúdo destes itens. Houve uma tendência das afirmativas, inicialmente escritas para contemplar os indicadores fisiológicos, serem interpretados como itens da fonte de aprendizagem vicária, sendo até mais representativos desta última fonte. No entanto, a estrutura fatorial adotada para a EFAEP apresentou índices ajustados de precisão e coerência teórica, indicando que o mesmo possui evidências de validade baseada na estrutura interna.

Ainda entre as limitações do estudo, o mesmo foi realizado com estudantes de uma única região do país e não foram exploradas outras formas de avaliação dos itens da EFAEP, como por exemplo, a realização de uma análise de juízes. Em futuras pesquisas com esta escala, sugere-se a revisão e formulação de novos itens e a verificação de suas propriedades psicométricas, bem como a sua aplicação em estudantes de outros estados brasileiros.

\section{Referências}

Ahn, H. S., Usher, E. L., Butz, A., \& Bong, M. (2016). Cultural differences in the understanding of modeling and feedback as sources of selfefficacy information. British Journal of Educational Psychology, 86(1), 112-136. doi:10.1111/ bjep. 12093

Ambiel, R. A. M., Noronha, A. P. P., \& Carvalho, L. F. (2015). Analysis of the Professional Choice Self-Efficacy Scaleusing Rasch-Andrich rating scale model. International Journal for Educational and Vocational Guidance, 15(3), 205219. doi:10.1007/s10775-015-9293-7

Ambiel, R. A. M., \& Noronha, A. P. P. (2012a). Autoeficácia para escolha profissional: Teoria, pesquisas e avaliação. Psicologia em Pesquisa, 6(02), 171-178. doi:10.5327/Z198212472012000200010

Ambiel, R. A. M., \& Noronha, A. P. P. (2012b). Escala de autoeficácia para escolha profissional. Manual Técnico. São Paulo, SP: Casa do Psicólogo.

Anderson, S. L., \& Betz, N. E. (2001). Sources of social self-efficacy expectations: Their measurement and relation to career development. Journal of Vocational Behavior, 58(1), 198-117. doi:10.1006/jvbe. 2000.1753

Azzi, R. G., Vieira, D. A., Iaochite, R. T., Ferreira, L. C. M., \& Guerreiro-Casanova, D. C. (2014). Crenças de eficácia pessoal e coletiva. In R. G. Azzi \& D. A. Vieira (Eds.), Crenças de eficácia em contexto educativo (pp. 15-40). São Paulo, SP: Casa do Psicólogo.

Bandura, A. (1977). Self-efficacy: Toward a unifying theory of behavioral change. Psychological Review, 84(2), 191-215. doi:10.1037/0033295X.84.2.191

Bandura, A. (1997). Self-efficacy: The exercise of control. New York: W. H. Freeman and Company.

Bandura, A. (2008). A teoria social cognitiva na perspectiva da agência. In A. Bandura, R. G. Azzi, \& S. A. J. Polydoro (Eds.), Teoria social cognitiva, conceitos básicos (pp. 69-96). Porto Alegre, RS: Artmed.

Bandura, A. (2009). Cultivate self-efficacy for personal and organizational effectiveness. In E. A. Locke (Ed.), Handbook of principles of orga- 
nization behavior ( $2^{\text {nd }}$ ed., pp. 179-200). New York: Wiley.

Betz, N. E., \& Luzzo, D. A. (1996). Career assessment and the career decision-making self-efficacy scale. Journal of Career Assessment, 4(4), 413-428. doi:10.1177/106907279600400405

Britner, S. L., \& Pajares, F. (2006). Sources of science self-efficacy beliefs of middle school students. Journal of Research in Science Teaching, 43(5), 485-499. doi:10.1002/tea.20131

Cohen, J., \& Cohen, P. (1983). Applied multiple regression/correlation analysis for the behavioral sciences ( $2^{\text {nd }}$ ed.). Hillsdale, NJ: Erlbaum.

Damásio, B. F. (2012). Uso da análise fatorial exploratória em psicologia. Avaliação Psicológica, 11(2), 213-228. Recuperado em http://pepsic. bvsalud.org/scielo.php?script=sci_arttext\&pid $=$ S1677-04712012000200007

Dancey, C. P., \& Reidy, J. (2006). Estatística sem matemática para psicologia: Usando SPSS para Windows. Porto Alegre, RS: Artmed.

Gainor, K. A., \& Lent, R. (1998). Social cognitive expectations and racial identity attitudes in predicting the math choice intentions of Black college students. Journal of Counseling Psychology, 45(4), 400-413. doi:10.1037/00220167.45.4.403

Hacket, G., \& Betz, N. E. (1981). A self-efficacy approach to the career development of women. Journal of Vocational Behavior, 18, 326-336. doi:10.1016/0001-8791(81)90019-1

Hampton, N. Z., \& Mason, E. (2003). Learning disabilities, gender, sources of efficacy, selfefficacy beliefs, and academic achievement in high school students. Journal of School Psychology, 41, 101-112. doi:10.1016/S00224405(03)00028-1

Iaochite, R. T., \& Azzi, R. G. (2012). Escala de fontes de autoeficácia docente: Estudo exploratório com professores de educação física. Psicologia Argumento, 30(71), 659-669. doi:10.7213/psicol.argum.7472

Joët, G., Bressoux, P., \& Usher, E. L. (2011). Sources of self-efficacy: An investigation of elementary school students in France. Journal of Educational Psychology, 103(3), 649-663. doi:10.1037/ a0024048

Lent, R. W., Brow, S. D., \& Hackett, G. (1994). Towards a unifying social cognitive theory of career and academic interests, choice and performance. Journal of Vocational Behavior, 45(1), 79-122. doi:https://doi.org/10.1006/jvbe.1994.1027

Lent, R. W., Lopez, F. G., Brown, S. D., \& Gore, P. A. (1996). Latent structure of the sources of mathematics self-efficacy. Journal of Vocational Behavior, 49, 292-308. doi:10.1006/ jvbe.1996.0045

Lopes, A. R., \& Teixeira, M. O. (2012). Projetos de carreira, autoeficácia e sucesso escolar em ambiente multicultural. Revista Brasileira de Orientação Profissional, 13(1), 7-14. Recuperado em http://pepsic.bvsalud.org/scielo.php?script=sci_ arttext\&pid $=$ S1679-33902012000100003

Matias, T. S., Rolim, M. K. S. B., Kretzer, F. L., Schmoelz, C. P., Vasconcellos, D. I. C., \& Andrade, A. (2009). Estilo de vida, nível habitual de atividade física e percepção de autoeficácia de adolescentes. Revista da Educação Física, 20(2), 235-243. Recuperado em http://periodicos.uem. br/ojs/index.php/RevEducFis/article/view/6413

Noronha, A. P. P., \& Ambiel, R. A. M. (2006). Orientação profissional e vocacional: Análise da produção científica. Psico-USF, 11(1), 75-84. Recuperado em http://www.scielo.br/pdf/pusf/ v11n1/v11n1a09

Nunes, M. F. O. (2008). Funcionamento e desenvolvimento das crenças de auto-eficácia: Uma revisão. Revista Brasileira de Orientação Profissional, 9(1), 29-42. Recuperado em http://pepsic. bvsalud.org/scielo.php?script=sci_arttext\&pid $=$ S1679-33902008000100004

Nunes, M. F. O., \& Noronha, A. P. P. (2008). Escala de auto-eficácia para atividades ocupacionais: Construção e estudos exploratórios. Paidéia (Ribeirão Preto), 18(39), 11-124. doi:10.1590/ S0103-863X2008000100011

Nunes, M. F. O., \& Noronha, A. P. P. (2011). Escala de Autoeficácia para Atividades Ocupacionais: Estudo da estrutura interna e precisão. Avaliação Psicológica, 10(1), 25-40. Recuperado em http://pepsic.bvsalud.org/scielo.php?script $=$ sci_ arttext\&pid $=$ S1677-04712011000100004

Pajares, F. (2002). Overview of social cognitive theory and of self-efficacy. Retrieved from http://www. emory.edu/EDUCATION/mfp/eff.html

Pajares, F., Johnson, M. J., \& Usher, E. L. (2007). Sources of writing self-efficacy beliefs of elementary, middle and high school students. Research in the Teaching of English, 42(1), 
104-120. Retrieved from http://sites.education. uky.edu/motivation/files/2013/08/PajaresJohnsonUsherRTE2007.pdf

Pajares, F., \& Olaz, F. (2008). Teoria social cognitiva e auto-eficácia: Uma visão geral. In A. Bandura, R. G. Azzi, \& S. A. J. Polydoro (Eds.), Teoria social cognitiva, conceitos básicos (pp. 97-114). Porto Alegre, RS: Artmed.

Patil, V. H., Singh, S. N., Mishra, S., \& Donavan, D. T. (2007). Parallel Analysis engine to aid determining number of factors toretain [Computer software]. Retrieved from http://ires. $\mathrm{ku} . \mathrm{edu} / \sim \mathrm{smishra} /$ parallelengine.htm

Prieto, G., \& Muñiz, J. (2000). Un modelo para evaluar la calida de los tests utilizados em España. Papeles del Psicólogo, 77, 1-10. Retrieved from http://www.papelesdelpsicologo.es/vernumero. asp?id=1102

Taylor, K. M., \& Betz, N. E. (1983). Applications of self-eficacy theory to the understanding and treatment of career indecision. Journal of Vocational Behavior, 22, 63-81. doi:10.1016/00018791(83)90006-4
Usher, E. L. (2009). Sources of middle school students' self-efficacy in mathematics: A qualitative investigation. American Educational Research Journal, 46(1), 275-314. doi:10.3102/0002831208324517

Usher, E. L., \& Pajares, F. (2006). Sources of science self-efficacy beliefs of middle school students. Journal of Research in Science Teaching, 43(5), 485-499. doi:10.1002/tea.20131

Usher, E. L., \& Pajares, F. (2008). Sources of self-efficacy in school: Critical review of the literature and future directions. Review of Educational Research, 78(4), 751-796. doi:10.3102/0034654308321456

Usher, E. L., \& Pajares, F. (2009). Sources of self-efficacy in mathematics: A validation study. Contemporary Educational Psychology, 34, 89-101. doi:10.1016/j.cedpsych.2008.09.002

Recebido: 25/06/2016

$1^{a}$ revisão: $17 / 11 / 2016$

$2^{a}$ revisão: $19 / 01 / 2017$ Aceite final: 19/01/2017

(C) $\mathrm{O}(\mathrm{s})$ autor(es), 2018. Acesso aberto. Este artigo está distribuído nos termos da Licença Internacional Creative Commons Atribuição 4.0 (http://creativecommons.org/licenses/by/4.0/), que permite o uso, distribuição e reprodução sem restrições em qualquer meio, desde que você dê crédito apropriado ao(s) autor(es) original(ais) e à fonte, forneça um link para a licença Creative Commons e indique se as alterações foram feitas. 